within 24 hours of removing the patch. No abnormalities of haemoglobin, W.B.C., platelet count, liver function, or blood urea were found during the course of the treatment.

\section{Discussion}

The results showed that intermittently applied $5 \%$ idoxuridine in $100 \%$ DMSO had a considerable effect on zoster (equal to that of $25 \%$ idoxuridine), both in shortening the healing time and in reducing the duration of zoster neuralgia. These results broadly agree with those of others (Juel-Jensen et al., 1970). Juel-Jensen and MacCallum (1972) funther suggested, however, that $40 \%$ idoxuridine in $100 \%$ DMSO, applied continuously on a dressing, gives even greater benefit. In view of the great expense of continuous application-up to $£ 60$ per patient (Juel-Jensen, 1973)-the good results from intermittent $5 \%$ idoxuridine application as described here, and the failure of $25 \%$ idoxuridine to give any greater benefit $5 \%$ idoxuridine in $100 \%$ DMSO applied four-hourly is probably satisfactory for noutine use. Idoxuridine $40 \%$ in $100 \%$ DMSO should be used only in the treatment of severe cases, under hospital supervision.

Systemic idoxuridine is potentially very toxic, panticularly to the bone marrow, and should therefore be reserved for lifethreatening conditions such as herpes simplex encephalitis. No systemic abnormalities have yet been described after therapy with topical idoxuridine in DMSO. None of our 118 patients developed any ovent signs of haematological, hepatic, or renal toxicity; the design of the trial did leave open the possibility of transient impairment of these organs during the early stages of treatment. Nevertheless, the absence of symptoms and signs of toxicity during this period, the subsequent normal results of investigations, and the absence of reported side effects all show the application to be safe. Since idoxuridine interferes with DNA synthesis and cell division it is on no account to be recommended for pregnant women, and it cannot be recommended for children until results of its use in them have been studied.

The patch tests showed that DMSO is a primary irritant, which probably explains the reponts of maceration of skin (Juel-Jensen and MacCallum, 1972), and even full-thickness skin loss (Dawber, 1973), after treatment with high concentrations of DMSO, which were applied very often for many days. Because treatment was intermittent only slight tender erythma occurred in a few patients in this study.

I should like to thank WB Pharmaceuticals Ltd, Fulton House, Empire Way, Wembley, for help with part of the trial and for supplying much of the idoxuridine and Julia Massey, systems analyst at North Staffordshire Hospital Centre, for invaluable statistical help.

\section{References}

Dawber, R. P. R. (1973). British Medical fournal, 1, 737

Juel-Jensen, B. E., MacCallum, F. O., Mackenzie, A. M. R., and Pike, M. G. (1970). British Medical fournal, 4, 776.

Juel-Jensen, B. E., and MacCallum, F. O. (1972). Herpes Simplex, Varicella and Zoster, p. 154. London, Heinemann.

Juel-Jensen, B. E. (1973). British Medical fournal, 1, 406.

Rapp, F., and Vanderslice, D. (1964). Virology, 22, 321.

Silk, B. R., and Roome, A. P. G. (1970). Lancet, 1, 411

\title{
Serum $\alpha$-Fetoprotein: Diagnostic Significance in Liver Disease
}

\author{
ERKKI RUOSLAHTI, MIKKO SALASPURO, HELENA PIHKO, LEIF ANDERSSON, \\ MARKKU SEPPÄLÄ
}

British Medical fournal, 1974, 2, 527-529

\section{Summary}

Raised serum $\alpha$-fetoprotein levels measured by radioimmunoassay were found in 19 out of $24(79 \%)$ patients with primary liver cancer and in 32 out of $311(10 \%)$ patients with other liver diseases. The rise was transient in cases of hepatitis and a transient rise was also seen after alcohol intake ceased in two patients with cirrhosis.

Department of Serology and Bacteriology, University of Helsinki, Finland

ERKKI RUOSLAHTI, M.D., Senior Lecturer in Immunology

HELENA PIHKO, M.D., Research Assistan

Department II of Medicine, University Central Hospital, Helsinki, Finland

MIKKO SALASPURO, M.D., Senior Physician

Department III of Pathology, University of Helsinki, Helsinki, Finland

LEIF C. ANDERSSON, M.D., Lecturer in Pathology

Department II of Obstetrics and Gynaecology, University Central Hospital, Helsinki, Finland

MARKKU SEPPÄLÄ, M.D., Senior Lecturer in Obstetrics and Gynaecology
$\alpha$-Fetoprotein levels exceeding $500 \mathrm{ng} / \mathrm{ml}$ were 30-50 times more common in primary liver cancer than in other liver diseases. A rise in level seems to reflect the extent of liver regeneration in liver diseases other than primary cancer.

\section{Introduction}

Primary liver cancer and teratocarcinomas are often associated with high circulating $\alpha$-fetoprotein levels. Concentrations down to normal (1-16 $\mathrm{ng} / \mathrm{ml}$ ) can be measured by radioimmunoassay (Ruoslahti and Seppälä, 1971; Chayvialle and Ganguli, 1973). Because of its sensitivity this method is of value not only in the diagnosis of primary liver cancer but also in detecting small rises in $\alpha$-fetoprotein level sometimes associated with other liver diseases, such as secondary liver cancer, hepatitis, and cirrhosis, with trauma, and with pregnancy (Elgort et al., 1972; Ruoslahti and Seppälä, 1972; Seppälä and Ruoslahti, 1972; Ruoslahti et al., 1972, 1973; Nishi and Hirai, 1973). The pathophysiology and the diagnostic significance of raised $\alpha$-fetoprotein levels in these conditions are not fully understood.

We have been using the radioimmunoassay test for $\alpha$ fetoprotein routinely for two years. We can now estimate the significance of various levels in the diagnosis of primary liver 
cancer, and our findings, reported here, suggest that in nonneoplastic conditions the $\alpha$-fetoprotein level reflects the extent of liver regeneration.

\section{Materials and Methods}

Serum $\alpha$-fetoprotein levels of patients with suspected primary liver cancer were determined as part of their clinical investigation. The final diagnosis and outcome were noted in a follow-up of each case. Diagnoses were based on clinical, laboratory, and histological findings. Liver or tumour tissue or both obtained for biopsy or at operation or necropsy was examined in 301 out of 335 cases, including all cases of primary or secondary liver cancer.

Serum $\alpha$-fetoprotein levels were determined by radioimmunoassay as described earlier (Ruoslahti and Seppälä, 1971). Levels above $10 \mathrm{ng} / \mathrm{ml}$ caused a detectable inhibition in the assay. Levels above $25 \mathrm{ng} / \mathrm{ml}$ were considered abnormal.

\section{Results}

Abnormal $\alpha$-fetoprotein levels ( $>25 \mathrm{ng} / \mathrm{ml}$ ) were found in 19 out of $24(79 \%)$ patients with primary liver cancer. The remaining five had normal levels. Levels were raised in 32 out of 311 $(10 \%)$ patients with other liver diseases (table). The highest levels found among both groups of patients are shown in the figure. Abnormal $\alpha$-fetoprotein levels were eight times more common in the primary liver cancer group of patients than in the non-cancer group, and the incidence of levels equal to or higher than $500 \mathrm{ng} / \mathrm{ml}$ was 42 times greater in the primary cancer group.

Incidence of Abnormal $\alpha$-Fetoprotein Levels in Various Liver Diseases

\begin{tabular}{|c|c|c|}
\hline Diagnosis & No. of Cases & $\begin{array}{c}\text { No. with Abnormal } \\
\alpha-F e t o p r o t e i n \\
(>25 \mathrm{ng} / \mathrm{ml})\end{array}$ \\
\hline $\begin{array}{l}\text { Primary liver cancer } \\
\text { Secondary liver cancer } \\
\text { Hepatitis: } \\
\text { Acute } \\
\text { Chronic } \\
\text { Cirrhosis } \\
\text { Fatty degeneration } \\
\text { Miscellaneous* }\end{array}$ & $\left.\begin{array}{r}24 \\
79 \\
25 \\
21 \\
61 \\
25 \\
100\end{array}\right\} 311$ & $\left.\begin{array}{r}19 \\
7 \\
5 \\
2 \\
9 \\
1 \\
8\end{array}\right\} 32$ \\
\hline
\end{tabular}

* Liver stasis, non-defined hepatomegaly, cholecystopathy, congenital disorders of bilirubin metabolism, haemochromatosis, non-defined hepatitis.

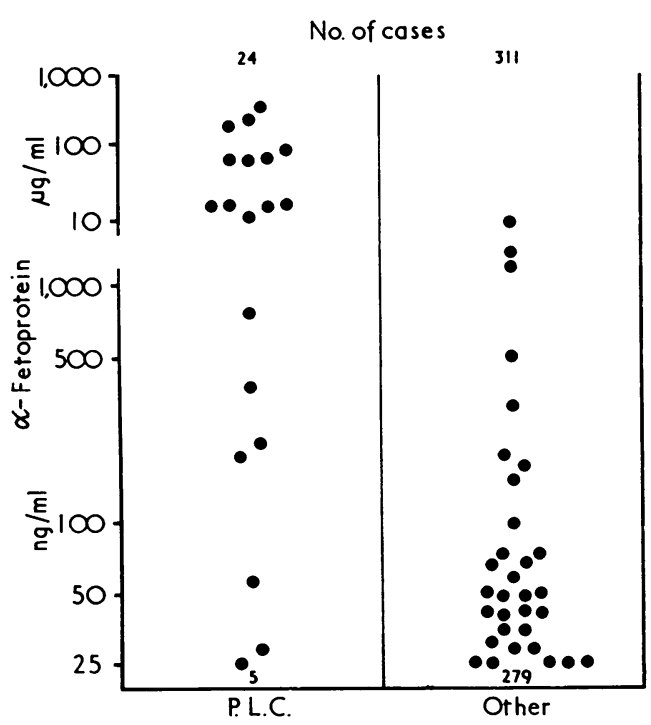

Serum $\alpha$-fetoprotein levels in patients with primary liver cancer (P.L.C.) and other liver diseases.
Serial estimations of $\alpha$-fetoprotein serum levels were done in eight patients with primary liver cancer, and in each case an initially raised level rose further with every test. On the other hand, two patients with primary liver cancer and normal $\alpha$-fetoprotein levels were followed up for 9 and 18 months respectively and no rise in levels was seen during these periods. Eight of the 32 patients with other liver diseases who had raised $\alpha$-fetoprotein levels were followed up with serial estimations and further increases in levels were found in two cases. In one, a case of ovarian cancer, the level rose from 5.7 to $7.5 \mu \mathrm{g} / \mathrm{ml}$, and in the other, a case of liver cirrhosis with no hepatoma found on necropsy, the level rose from 2.7 to $3.1 \mu \mathrm{g} / \mathrm{ml}$. Levels decreased in six cases. In two of cirrhosis a temporary increase in level after withdrawal of alcohol was associated with an improvement in clinical condition. Two patients with acute hepatitis and resulting hepatic coma had levels of 525 and $4,000 \mathrm{ng} / \mathrm{ml}$ respectively. The latter patient recovered and his $\alpha$-fetoprotein level returned to normal.

\section{Discussion}

Recent work has shown that $\alpha$-fetoprotein may be present in the serum of normal persons (Ruoslahti and Seppälä, 1971) and of those with diseases other than primary liver cancer (Abelev et al., 1971; Ruoslahti and Seppälä, 1972; Nishi and Hirai, 1973), especially those with gastrointestinal malignancies and conditions associated with liver regeneration. Whether associated with metastases or not malignant growths other than primary liver cancer seem to be associated with $\alpha$-fetoprotein levels that are generally under $500 \mathrm{ng} / \mathrm{ml}$ (Ruoslahti and Seppälä, 1972; Nishi and Hirai, 1973). Values above $500 \mathrm{ng} / \mathrm{ml}$ constitute the zone where the diagnostic value of $\alpha$-fetoprotein in primary liver cancer is greatest. We have not seen enough cases of cholangiocarcinoma or mixed-type carcinoma to be able to comment with certainty on possible differences between the $\alpha$-fetoprotein levels in these cases and those in cases of hepatocellular cancer. In a series of 14 cases of hepatocellular cancer one was classified as possibly cholangiogenic (Ruoslahti et al., 1972). The $\alpha-$ fetoprotein level was $12 \mu \mathrm{g} / \mathrm{ml}$. Two cases in the present study had $\alpha$-fetoprotein levels of 15 and $74 \mu \mathrm{g} / \mathrm{ml}$. The conclusion, if any, from this would be that the cholangiocellular type does produce $\alpha$-fetoprotein and that the different types of primary liver cancer probably do not differ in this respect.

Though abnormal $\alpha$-fetoprotein levels do occur in many liver diseases it is still appropriate to emphasize their relative specificity for primary liver cancer. The increase of $\alpha$-fetoprotein levels has been transient in all cases of acute hepatitis studied after recovery (Abelev, 1971; Ruoslahti et al., 1973). Repeated determinations over a period of time will therefore increase the diagnostic reliability of levels of $\alpha$-fetoprotein-normal or fluctuating values suggesting a benign process, rising levels (unless the tumour is removed) being characteristic of malignancy. Tumours other than primary liver cancer or teratomas do occasionally produce $\alpha$-fetoprotein. Akai and Kato (1973) have described two cases of gastric cancer with no demonstrable liver involvement in which the serum $\alpha$-fetoprotein level was raised. One of our cases was a pancreatic cancer with a normal liver and an $\alpha$-fetoprotein level of $40 \mathrm{ng} / \mathrm{ml}$. Possibly the high level $(7 \cdot 7 \mu \mathrm{g} / \mathrm{ml})$ found in our patient with ovarian cancer was due to $\alpha$-fetoprotein produced by the tumour, but since there were liver metastases we cannot be sure.

Experimental hepatic injury in mice and rats causes a rise in serum $\alpha$-fetoprotein levels during the regenerative phase (Bakirov, 1968; Ruoslahti et al., 1974) and a positive correlation between the level and the extent of liver regeneration has recently been established in mice ( $\mathrm{H}$. Pihko, to be published). Raised levels in non-malignant liver diseases also seem to be associated with regeneration of the liver. This is supported by the association of raised levels with the improvement in the condition of our two patients with cirrhosis and the recovery phase of hepatitis in some of the present and other reported cases 
(Abelev, 1971; Ruoslahti et al., 1973). We have seen two cases of hepatic coma, caused by an acute hepatitis, in which $\alpha$-fetoprotein levels were 150 and $350 \mathrm{ng} / \mathrm{ml}$ respectively, and the two cases of coma in the present study had levels of 525 and $4,000 \mathrm{ng} / \mathrm{ml}$ respectively. It may be significant that the patient with the highest level was the only one who recovered. More extensive studies will be needed to establish the consistency and possible diagnostic significance of a correlation between the extent of the regenerative response and the $\alpha$-fetoprotein level in man.

\section{References}

Abelev, G. I. (1971). Advances in Cancer Research, 14, 295.
Abelev, G. I., et al. (1971). Byulleten' Eksperimental'noi Biologii i Mediciny,

Akai, 3., and Kato, K. (1973). Gann Monograph of Cancer Research, 14, 149. Bakirov, R. D. (1968). Byulleten' Eksperimental'noi Biologii i Mediciny, 2, 45. Chayvialle, J. A. P., and Ganguli, P. C. (1973). Lancet, 1, 1355.

Elgort, D. A., Abelev, G. I., and O'Connor, G. T. (1972). International fo: D. Anal of Cancer, 10, 331.

Nishi, S., and Hirai, H. (1973). Gann Monograph of Cancer Research, 14, 79.

Ruoslahti, E., and Seppälä, M. (1971). International fournal of Cancer, 8, 374.

Ruoslahti, E., and Seppälä, M. (1971). International fournal of Cancer, 8, 374 Ruoslahti, E., and Seppälä, M. (1972). Lancet, 2, 278.

Ruoslahti, E., Seppälä, M., Vuopio, P., Saksela, E., and Peltokallio, P. (1972). Fournal of the National Cancer Institute, 49, 623.

Ruoslahti, E., Seppälä, M., Räsänen, J., Vuopio, P., and Helske, T. (1973). Scandinavian Journal of Gastroenterology, 8, 197.

Ruoslahti, E., et al. (1974). Proceedings of $7 t h$ Miles Symposium. Baltimore,
Md. In press. Seppälä, M., and Ruoslahti, E. (1972). Lancet, 1, 375.

\title{
The Kidney and Intravascular Coagulation in Myelomatosis
}

\author{
A. MILFORD WARD, F. E. PRESTON
}

British Medical fournal, 1974, 2, 529-531

\section{Summary}

In 15 out of 35 patients with myelomatosis histological examination showed intravascular fibrin within the glomeruli, and this was associated with proliferation of the mesangial complex in 12. The presence of intravascular fibrin and mesangial proliferation was not associated with any specific immunoglobulin abnormality or with the presence or absence of Bence Jones proteinuria. In addition to fibrin being present within glomerular capillaries it was also shown in intertubular capillaries in three cases of myelomatosis with acute tubular necrosis. It is suggested that intraglomerular coagulation and fibrin deposition may contribute to the genesis of renal failure in myelomatosis.

\section{Introduction}

Renal failure is a common complication and a not infrequent cause of death in myelomatosis (Medical Research Council, 1973), there being a continuous spectrum of changes from minimal functional impairment to acute oliguric failure. The currently accepted causes of renal failure in myelomatosis include hypercalcaemia, pyelonephritis, "myeloma kidney," and amyloidosis (Hobbs, 1971). Hobbs has also shown that whereas the proportion of myelomatosis deaths due to renal failure used to exceed $30 \%$ modern cytotoxic therapy has reduced this to $15 \%$, but $10 \%$ still present with irreversible renal failure and die within the first two months of therapy. A high blood urea at the time of initial presentation is a grave prognostic sign (Peto, 1971). Other reponts have suggested that some patients with myelomatosis develop coagulation anomalies (Vigliano and Horowitz, 1967), abnormalities of fibrin polymerization (Lackner et al., 1970), and a hypercoagulable state as shown by an increased incidence of thromboembolism (Catovsky et al., 1970) and by diminished fibrinolysis (Preston and Lee, 1972). In the light of these con-

\footnotetext{
Department of Immunology, The Medical School, Hallamshire
Hospital, Sheffield S10 $2 \mathrm{R}$.

A. MILFORD WARD, M.B., M.R.C.PATH., Senior Lecturer and Honorary Consultant

University Department of Haematology, Royal Infirmary, Sheffield S6 3DA

F. E. PRESTON, M.D., M.R.C.PATH., Consultant Haematologist
}

siderations and in view of the increasing incidence of fibrin in the pathogenesis of the glomerulopathies and awareness of the importance of this fact (Clarkson et al., 1971) the possible role of fibrin in the genesis of the renal lesion in myelomatosis was investigated initially by a retrospective light and immunofluorescent microscopical study.

\section{Methods}

Renal tissue was obtained by percutaneous needle biopsy in three cases and at necropsy from a further 32 cases of myelomatosis. Control tissues were obtained at necropsy from five patients with no evidence of myelomatosis or renal disease. Tissue for light microscopy was fixed in $10 \%$ formol saline, and $5-\mu \mathrm{m}$ sections embedded in paraffin were stained with haematoxylin and eosin, Martius scarlet blue, periodic-acid Schiff, periodic-acid silver methamamine, Sirius red, and picro-Mallory. When available a further sample of tissue was snap-frozen and $3-\mu \mathrm{m}$ cryostat sections cut for immunofluorescent examination. These sections were examined by direct immunofluorescence, using F.I.T.C. conjugated rabbit antisera specific for human fibrin and fibrinogen, kappa and lambda immunoglobulin light chains, and IgG, IgA, IgM, and IgD heavy chains. The immunological specificity of the staining was tested by the "blocking effect" of pretreatment with unlabelled antibody.

The case records were reviewed and biochemical, haematological, and immunochemical data correlated with the histological findings.

\section{Results}

\section{LIGHT MICROSCOPY}

In eight out of the 35 cases light microscopy showed evidence of metastatic calcification either in the epithelium of tubular cells or in the interstitium, 13 cases showed evidence of pyelonephritis, and 12 cases showed the classical appearances of "myeloma kidney" with laminated casts and epithelial syncytia in the distal tubules. Only two cases showed stainable amyloid. The glomeruli showed evidence of mesangial proliferation in 16 cases, though there was no evidence of epithelial or juxtaglomerular proliferation. Fifteen cases showed fibrin deposition on the endothelium of the glomerular capillaries, three cases also showing occulsion of intertubular capillaries by fibrin thrombi and acute tubular necrosis 